\title{
Por un diálogo con la fotografía digital ambien- tal desde la educación primaria
}

\section{Resumen}

Universidade de Cádiz (Espanha)

La fotografía digital es un recurso que se utiliza poco en la educación primaria. La educación ambiental es un contenido que se aborda de modo puntual en el currículo. De modo que proponemos el diálogo como herramienta pedagógica, además de la escucha activa, así como vincularlo a la cultura slow, con la intención de que el alumnado y el profesorado se tome su tiempo para mirar o admirar, para realizar o compartir una fotografía. Y nuestra propuesta didáctica pasa por llevarse a cabo con el teléfono móvil y se continúe con ponerle voz a la fotografía y describirla. Pero sin olvidarnos de que una fotografía digital ambiental dice mucho de quien la hace, de su sensibilidad, de su propuesta y su motivación. Innovar se puede interpretar en el aula como una antesala para motivar. Y la fotografía digital ambiental en educación primaria ha de dar grandes lecciones magistrales al respecto.

Palabras clave: Educación primaria. Educación ambiental. Diálogo. Didáctica.

\section{Por um diálogo com a fotografia digital ambiental desde a educação primária}

\section{Resumo}

A fotografia digital é um recurso que se utiliza pouco na educação primária. A educação ambiental é um conteúdo que se explica de modo pontual no currículo. Quer dizer, vamos propor o diálogo como primeira ferramenta pedagógica, aliás, da escuta ativa e sua vinculação à cultura slow, como a intenção de que o aluno e o professor possam tomar seu tempo para mirar e admirar, para realizar e compartilhar uma fotografia. E nossa proposta didática passa por ser feita com o celular e se continue com coloca-lhe voz à fotografia, fazer que ela se descreva. Mais sem esquecer que uma fotografia digital ambiental diz muito de quem fê-la, de sua sensibilidade, de sua proposta e de sua motivação. Em certo modo, inovar pode se interpretar na aula como um passo prévio à motivação. E a fotografia digital ambiental em educação primária vai dá-nos grandes lições magistrais.

Palavras chave: Educação primária. Educação ambiental. Diálogo. Didática. 
Por un diálogo con la fotografía digital ambiental desde la educación primaria

\section{For a dialogue with digital environmental photography from primary school}

\section{Abstract}

Digital photography is a resource that is rarely used in primary education. Environmental education is a content that is addressed in a timely manner in the curriculum. To this end, we propose dialogue as the first pedagogical tool, in addition to active listening, as well as linking it to slow culture, with the intention that students and faculty take their time to watch or admire, to make or share a photograph. And our didactic proposal is to carry out with the mobile phone and continue to put voice to the photograph, to make it describe itself. But let us not forget that a digital environmental photograph tells a lot about who makes it, about its sensitivity, its proposal and its motivation. In a way, innovation can be interpreted in the classroom as an anteroom for motivation. And environmental digital photography in primary education must give great lessons.

Key words: Primary education. Environmental education. Dialogue. Didactic.

El diálogo y la construcción compartida del saber

(Maribel Pomar)

\section{En el centro de la mirada}

Educar es una de las labores más complejas que el ser humano puede encontrar y desarrollar en su devenir. En la historia de la educación se han posibilitado muchos recursos para la mejora de su práctica. Cabría añadir que en las últimas décadas se ha introducido desde las páginas web a imágenes en movimiento de realidad aumentada (CABERO; GARCÍA, 2016), pasando por el 3D o el multimedia interactivo. Y nosotros ahora proponemos la utilización de la fotografía digital (NAVARRO, 2019) como una posibilidad. Asimismo, un hecho primordial para la educación es que ha de estar cercana a la contemporaneidad y que ha de dar respuesta a las demandas del alumnado del siglo XXI (CABERO, 2016). Con ello, la fotografía digital no difiere, a priori, mucho de la fotografía en formato analógico. Los principios sobre los que se asientan son muy similares (sea de composición o estética) aunque, la fotografía digital, se ha hipersimplificado y es inmediata. Mirar a través del visor se ha diversificado a raíz de sus prestaciones para el usuario, quien gracias a la pantalla observa y participa de la realidad (RIVAS, 2018), retocándola o transformándola. 
Igualmente, de un tiempo para acá, otro aspecto que podemos añadir en relación con la fotografía digital es la proliferación de prestaciones en el teléfono móvil; lo que no quita el uso de la cámara digital convencional. No obstante, nuestra propuesta de intervención sería con el dispositivo inalámbrico que almacena o transfiere la fotografía, pudiéndola subir a la nube, o bien cabe la posibilidad de adaptarla al gusto de los demandantes. Una fotografía que ha sido motivo de estudio y abordaje científico (de lo social a lo ambiental) en pro del conocimiento (TÓJAR; RODRÍGUEZ, 2013; GARCÍA, 2013 ; TRINQUELL, 2015; RODRÍGUEZ-ORTIZ; MONTOYA-TRUJILO, 2020).

Consideramos el valor de una fotografía digital que está en la mira de miles de usuarios, de todas las edades, a los que hay que educar en el uso idóneo de esta herramienta. Produciendo un efecto en quién la observa que puede sensibilizar, conmover $\mathrm{O}$, simplemente, alertar sobre una problemática. Según Barthes (1990, p. 81): "En el fondo la fotografía es subversiva, y no cuando asusta, trastorna o incluso estigmatiza, sino cuando es pensativa". Y, en este caso, nuestro centro de interés lo iremos a circunscribir sobre la temática ambiental. Una sensibilidad que no puede estar ajena de los diferentes niveles educativos y, en efecto, una educación actual pasa por darle cobertura.

Como curiosidad los planes de estudios de educación primaria, en la región de Andalucía (España), cuenta con unas asignaturas (áreas de ciencias sociales, lengua y literatura, educación artística, lengua extranjera, educación física, cultura y práctica digital) que permiten el aprendizaje con la fotografía. Un contenido que se puede diversificar en tres segmentos, ya que el primero estaría centrado sobre el conocimiento de la fotografía y su mejora técnica. Mientras que el segundo priorizaría la necesidad de realizarla a partir de los adquirido en la primera sesión. Y, por último, promoveríamos ver y compartir fotografías con otros compañeros o maestros, además de abrir la experiencia a la comunidad educativa en general.

Tal vez, lo ambiental sea el pretexto idóneo para empezar a hablar de fotografía digital. Pero, bajo nuestra consideración, lo ambiental lo es todo: nuestro contexto más inmediato, la naturaleza a la que amamos o agredimos, los animales en extinción, la vegetación que arde o replantamos, el agua que derrochamos, una mina abandonada, las industrias que contaminan, los tramos de la vía del tren o las carreteras, los residuos urbanos, el derecho o los desechos alimenticios... Y, además, nosotros mismos en la cotidianeidad en nuestra ciudad o pueblo. 
Por ello, establecemos una educación ambiental: A) que se ha de centrar en las personas, en la comunidad, en la sociedad en su conjunto y no, exclusivamente, en el medio; planteándose como una propuesta certera de cambio en la sociedad y de mentalidad. B) que contribuya a que los estudiantes sepan analizar e interpretar, comprender y conocer la complejidad de los problemas que aquejan al mundo, algunos de dimensiones globales, mientras que otros son más cercanos. C) que fomente entre el alumnado la vida sostenible, equilibrada y saludable, así que conozca y reconozca los cambios desde sociales a económicos, de políticos a culturales. D) que con la intención de la mejora ambiental pase por un progreso proporcionado, igualmente, en el ámbito social, económico o político; sea a nivel local o planetario (ÁLVAREZ; VEGA, 2009).

Con todo, estamos dando a comprender dos apartados iniciales: $\left.1^{\circ}\right)$ la necesidad de aprender fotografía desde la formación más elemental y ${ }^{\circ}$ ) lo beneficioso que ha de ser introducir, en el amplio sentido del término, lo ambiental desde la educación primaria.

Y como último eslabón en esta parte introductoria, cabría señalar que pese a que la inmensa mayoría del alumnado de primaria es considerado como nativos digitales por el hecho de haber nacido ya en el transcurrir del siglo XXI y estar inscritos en el censo de los que crecen con las tecnologías de la relación, la información y la comunicación (TRIC)... Se hace necesario atenderlos, en algún momento, como novatos digitales. El hecho de haber nacido en y con el desarrollo de las tecnologías no lo exime de conocerlas con propiedad y reconocer que el mercado cambia y las prestaciones no son las mismas, por lo que las necesidades de aprendizaje, igualmente, han cambiado (APARICl; GARCÍA, 2018). Las tecnologías han venido para quedarse y transformar el panorama educativo (MARTA-LAZO; GABELAS, 2016), inspirado en un continuo saber social e estimulando en valor de las relaciones humanas.

\section{Importancia del diálogo en la educación primaria}

En educación primaria se hace imprescindible el aprendizaje entre iguales (AVELLO-MARTíNEZ; MARÍN, 2016), pues lo que se pretende es que el saber sea fruto de una elaborada transformación personal y grupal. A partir de este momento, estamos dotando de un valor epistemológico al otro, tal vez, 
igual al nuestro. Y se produce un resultado educativo: se pasa de la jerarquía unilateral a la heptarquía multidireccional. Y la verdad comienza a entrar en acción en el seno del aula y, probablemente, aparezca el error, pero con la posibilidad de quedar subsanado por parte del maestro o la maestra. La pericia nos ha de evidenciar que lo contrario a la equivocación, pues el alumnado puede estarlo, no es el error sino la mentira que puede ir teñida de omisión. Además, en algún momento, la equivocación forma parte del proceso de aprendizaje.

Con todo, el docente debe convencerse de que no hay verdad sino verdades $y$, a partir de este momento, la fotografía adquiere su función didáctica (RIGO, 2014), ya que la dotamos de ello, a través del uso del diálogo y la escucha activa. El profesorado percibe la dificultad del alumnado y facilita su aprendizaje. Y la duda se instala en el proceso metodológico como una manera de seguir aprendiendo, de saber más. Pues aquí y ahora el aprender mediante la acción de inquirir se apodera del proceso y, ojalá, el estudiante salga del aula con más preguntas que posibles respuestas. A la postre, inquirir lo hacemos coincidir con aprender haciéndose preguntas.

Será la fotografía, junto con nuestra sensibilidad profesional, lo que convierta a la enseñanza en un espacio de aprendizaje colectivo y social, permitiendo que el estudiante se vea involucrado en su propio proceso. Lejos quedaría aquel alumnado pasivo que toma nota de lo que el profesor dicta o transmite en el aula y tras un solitario proceso de memorización ha de devolver el día del examen lo adquirido y plasmarlo en la prueba escrita. Y cuanto más se asemeje lo dicho por el maestro con lo redactado por el alumno más alta será la calificación. No obstante, la propuesta con la fotografía se hace diferente pues la hemos de inspirar en la participación frente al proceso formativo exclusivamente en solitario. En el ejercicio de superación de la mera memoria optamos por la comprensión, en contribuir a un alumnado crítico y reflexivo frente a otro pasivo y repetidor de contenidos instrumentales...

La fotografía se erige en protagonista. A la postre, participamos de un quehacer que incentiva a un alumnado autocrítico y responsable siendo, en parte, la clave de la educación ambiental (CANTÚ-MARTíNEZ, 2014). Pues siendo autocrítico no somos consumidores que caemos en el consumismo llevados por la impulsión de la moda o la publicidad, sino que nos convertimos en responsables como un modo de ser y hacer, proceder y sentir en la vida... De compromiso ambiental. 
Por un diálogo con la fotografía digital ambiental desde la educación primaria

El diálogo se apodera del proceso de enseñanza-aprendizaje y la situación de respeto por las partes involucradas es incuestionable. Y durante el transcurrir del aula el feed black se manifiesta como la puesta en común de lo elaborado. Mientras que una estrategia didáctica podría ser el flipped classroom (o aula invertida) en el cual los estudiantes acceden a los contenidos desde su hogar, a través de tutoriales, vídeos o podcast y en la clase se utiliza el tiempo para realizar actividades y, sobre todo, para el intercambio de opiniones o ideas, aclarar dificultades o dudas, establecerse soluciones o conocimientos entre el alumnado (AYALA, 2014).

Estamos ante un quehacer compartido donde se evidencia la fluidez en el procedimiento a partir de unos entornos flexibles, en el cual lo que se prioriza es la comprensión de los contenidos y el aprendizaje está centrado sobre un alumnado motivado. Aunque la observación participante del profesorado, también, es importante. La base de este modelo de aprendizaje está inspirada en la corresponsabilidad y en el diálogo. Sin embargo, cabría la posibilidad de buscar cierto riesgo en que el alumnado en su casa no cuente con la confortabilidad para trabajar o no tiene las herramientas para llevarlo a cabo. En el primero de los casos, el docente debe saber ampliarle la zona de confort, 6 pues si en su casa cuenta con dificultades, que las bibliotecas se conviertan en un espacio tutorizado y dialógico, que "[...] se abren fuera del horario escolar para acoger a los estudiantes que quieran participar y ayudarles en su aprendizaje escolar (estudio, explicaciones, búsqueda de información, elaboración de trabajos...) con la ayuda de personas mayores (familias, profesorado, voluntarios, estudiantes, mayores...)" (BILBAO; MARAURI 2012, p. 108). Mientras que si no se dispone de cámara o teléfono digital se pueden llegar a compartir en el momento del trabajo por equipo; o bien, la escuela se ha de mostrar como un lugar garantista y facilitador del recurso. La idea es que todos y todas tengan las mismas posibilidades de entrar y las mismas probabilidades de salir con éxito del sistema educativo.

La importancia de saber presentar, orientar e ilusionar el trabajo y estudio del discente es función del docente. En este sentido, se puede inspirar en el poder de la fotografía digital, para empezar a dar a comprender su labor, para que el alumnado vaya investigando y cree un resultado final, a modo de un producto, y sea capaz de defenderlo públicamente (FISHER, 2013). En este ejercicio de aprendizaje compartido, las imágenes fotográficas pueden ser realizadas por ellos o por otros autores. Y la fotografía se convierte en un pretexto 
para crear situaciones de aprendizaje. Y el diálogo es un agente que activa el conocimiento y la posibilidad para saber más.

\section{Del enseñar al aprender con la fotografía}

Es cierto que no es lo mismo mirar que admirar. A nuestro alumnado hemos de incentivarle ambos quehaceres. Es decir, de las doce acepciones que considera la real academia de la lengua española sobre el verbo mirar, destacaríamos en nuestro discurso el de dirigir la vista a un objeto, además del que hace alusión a revisar o tener en cuenta, con la intención de atender, algo que nos lleva a pensar e incluso a juzgar o buscar información sobre eso que nos ha llamado la atención. Mirar puede derivar hacia la necesidad de inquirir y desarrollar una especial predilección por ese objeto a estudio. Pero mirar sería el primer estadio con la fotografía en la educación ambiental pues, seguidamente, se hace pertinente el hecho de admirar que desprendiéndola de la causa que sorprende, abrazamos la de contemplar haciendo alarde de lo agradable que nos llama la atención. Ya que en ella hay un especial aliciente, que hace que la destaquemos sobre su entorno. Es decir, posee en el fondo un matiz extraordinario y, por ello, nos conmueve.

Enseñar a mirar ha de ser tan útil como aprender a admirar. La pretensión de mirar debería ser un primer paso que el alumnado podría conocer la orientación y motivación por parte del docente. Mientras que admirar, se ha de dejar para que el estudiante, solo o en grupo, sea capaz de extraer sentido de lo que miró, haciéndolo suyo, valorándolo y considerándolo. Es lo que se había mencionado en el párrafo anterior como "conmueve". Pero ahora con el matiz de motivar al alumnado.

Enseñar es promover una situación de aprendizaje y la fotografía posee muchos de los ingredientes que necesita el contexto convencional de la educación. La fotografía impulsa el desarrollo del diálogo en el aula, realiza la labor pertinente para que el saber se ponga en movimiento (SALKELD, 2014 ; JEFFREY, 201 1). La estrategia de dinamizar la opinión se incentiva con la fotografía que con su poder polisémico estimula el propósito de que el conocimiento aumente $y$, a la vez, mejore.

En este sentido, proponemos mirar y, luego, admirar (BERGER, 2015; MARZAL, 2008). Enseñar a mirar con una actitud activa pasa por buscar, 
Por un diálogo con la fotografía digital ambiental desde la educación primaria

seleccionar y evaluar el posible objeto de estudio. Mientras que admirar llevaría implícito la necesidad de contrastar, actualizar y compartir la pieza fotográfica elegida. Dos propuestas que aglutinamos en una acción: la del enseñar a aprender con la fotografía.

\section{Fotografía digital en educación ambiental}

Fotografiar, por ejemplo, el árbol que está en el patio del colegio o aquellas casas bajitas que están no muy lejos del centro educativo de primaria, es contribuir a la educación ambiental. $\bigcirc$ bien, recuperar aquella postal del río por su paso por nuestro municipio y que hemos encontrado en un archivo de fotografía o en la web... Son ejercicio de educación ambiental, de puesta en valor del patrimonio (CAMBIL; TUDELA, 2017), de sensibilización, de no olvidar u omitir. Pues con la fotografía ampliamos nuestra visión de la educación ambiental. En el sentido, que aumentamos nuestra capacidad de análisis y criticidad; del mismo modo que se comienza a dejar atrás a un alumnado pasivo, que se ve ahora incrementado por su desarrollo del sentir creativo (LÓPEZ-MARTíNEZ; NAVARRO-LOZANO, 2010). Desde este momento, una idea empieza a vagar y asentarse sobre las convicciones del alumnado, ya que éste ha de seleccionar la mirada a través de su pantalla y saber dar a comprender sus intenciones educativas-ambientales. Sea para sensibilizar o alarmar, para denunciar o mostrar una situación o una idea, etc. El alumno aprende haciendo, se convierte en el hacedor y la cámara pasa a ser un útil de aula, superándose la exclusividad de usarse como un mero instrumento. Este estudiante de primaria comienza a aprender a aprender $y$, asimismo, aprende haciendo.

Ante el sinnúmero de cambios que se han producido en los últimos años a partir del advenimiento y desarrollo de las tecnologías en la educación se hace necesario un paso al frente en la manera de enseñar pero, igualmente, en cómo y qué enseñar. Algo que dará como resultado el para qué enseñar. Y, es por ello, que sugerimos abrazar a la fotografía digital para comenzar este recorrido por la educación ambiental (FREEMAN, 20 16). Siendo esta disciplina un saber que hemos de impartir de modo transversal. No se puede seguir reduciendo lo ambiental a lo exótico o a lo verde. La educación ambiental es un saber imprescindible que se debe impartir desde la escuela primaria con convicción y conocimiento. Por ello, no vale cualquier docente para su 
implementación. Es decir, no sería reproduciendo los contenidos de un libro de texto o de una guía didáctica. En todo caso, es necesario un saber relacionar los contenidos con la realidad y el currículo.

La educación ambiental nos encamina hacia un saber social y cotidiano, versátil y flexible que se ancla a la evidencia de lo que realmente debemos enseñar (HERRÁN, 2017). Estamos pensando en contribuir a una ciudadanía del siglo XXI responsable y responsabilizada de los cambios ambientales y las consecuencias que pueden conllevar el delirio extremo hacia donde nos encaminamos.

Si social y económicamente se ha producido un cambio a nivel planetario, éste se ha de introducir en el seno del aula y de la escuela en sí. Sin perder del horizonte la función transformadora de la educación, en un contexto poliédrico en continua construcción; al que no se ha de mirar para otro lado (SUBIRANA, 2015).

Y, a partir de este momento, hablamos de tecnología y educación ambiental. Con un resultado que sería la fotografía digital ambiental en la educación primaria. El foco de la fotografía digital y ambiental en educación primaria ha de estar presente. Estamos ante un reto que se ha de evidenciar con la puesta en valor y práctica por una comunidad educativa sensible y sensibilizada por los temas ambientales que tienen una dimensión global y, a la vez, local... Como podrían ser los desastres ecológicos o las migraciones, los refugiados ambientales o las hambrunas, las epidemias o la desertización, la contaminación o el mar, la ciudad o el campo... Y, curiosamente, todos estos aspectos que hemos mencionado, de una u otra manera, son contenidos del currículo de primaria. Aunque, eso sí, no existe una asignatura propia y con propiedad que aborde los temas ambientales... Al menos, hasta el momento... Y, por consiguiente, en poco contribuimos al desarrollo integral del alumnado.

\section{La conjugación del verbo fotografiar}

Una conjugación verbal es la correlación de los pronombres personales y una acción. En este caso, para suscitar uniones con el verbo fotografiar proponemos las conexiones con el presente de indicativo. Y, a partir de ahí, estableceremos posibles relaciones. Es decir, el verbo fotografiar se presenta como acción y los diferentes pronombres personales, en cierto modo, 
Por un diálogo con la fotografía digital ambiental desde la educación primaria

manifiestan una actividad para el ejercicio didáctico de incluir la fotografía digital ambiental en la dinámica de aula.

Empezaremos con, yo fotografío. Yo, en este caso, nos referiremos al maestro de primaria. Un profesional de la educación del que siempre reivindicamos saber $y$ tener capacidad para transmitir $y$, por ello, es un profesional cualificado. Posee suficiente capacidad y formación profesional y no solo conocimientos curriculares. Sabe de didáctica, pedagogía y psicopedagogía. Por ello, su manera de presentar la tarea es dándola a comprender, a través de propósitos posibles y motivadores para el alumnado. Se toma su tiempo, pues todo está en función del grupo-clase y es una persona implicada con la educación y, por ello, conoce igualmente el contexto.

Le sigue, tú fotografías. Ahora es el alumnado quien toma la iniciativa y realiza una fotografía. Según las indicaciones compartidas por el docente, cuenta con nociones sobre la realización de una fotografía. Se preocupa del enfoque, de la luz, del encuadre y, sobre todo, del contenido. Sabe que la instantánea es un momento de la realidad congelada. No duda de la intencionalidad de la fotografía. Tal vez, la estética y la ética han de estar presente en este ejercicio de clase. Pero su preocupación ha de estar en saber expresarse con el recurso fotográfico.

Sin duda, ahora vendría, él fotografía. Supone un quehacer de escucha y observación de lo que su compañero o compañera han fotografiado. Significa ponerse en el papel del autor, adquiriendo la singularidad de coautor, pues nuestra consigna es la de participar de la obra, quizás, no realizándola; ya que pertenece a ese otro igual pero sí sugiriendo y aportando consideraciones de mejora. La teoría de la recepción (UAUSS, 2012) se evidencia y la corresponsabilidad de mejora se activa entre las partes, pues el aula les pertenece al igual que los resultados en forma de producto cultural.

A renglón seguido, le toca a, nosotros fotografiamos. Una actividad compartida. En el grupo clase, pongamos como ejemplo, se programa una salida para fotografiar la naturaleza. Lo ambiental será el motivo de la fotografía y la creatividad el leitmotiv de la iniciativa pedagógica. Cada alumnado hará sus fotografías. Y tras un ejercicio de reflexión se subirán a la nube. En sus casas los chicos podrán consultar los ejercicios de los demás para que, al día siguiente de clase, poder debatir con los demás y elegir la que será la 
fotografía seleccionada para, por ejemplo, el cartel del día internacional del medio ambiente (5 de junio).

Y ahora, la propuesta se centra sobre, vosotros fotografiáis. Si en la primera persona del singular el docente explicaba lo qué había y cómo había que hacer la fotografía; para luego dar paso a las características del trabajo, exponer los criterios de evaluación, etc. Es decir, era una especie de master class ofrecida por el responsable del aula. En este momento, es de nuevo el maestro quien toma la iniciativa y propone que van a hacer determinado tipo de fotografía. Por ejemplo, una fotografía urbana sobre el tráfico; o bien una rural sobre el tipo de cultivo en determinada estación del año y su producción, envasado y venta al público... La idea es trabajar, en grupo o personalmente, pero teniendo claro qué hacer, pues ya saben cómo hacerlo.

Por último, le toca el turno a, ellos fotografían. Es posible invitar a un grupo de alumnado de otro centro o nivel educativo para compartir sus trabajos creativos con nuestro alumnado, y viceversa. Aquí se puede, incluso, organizar juntos una salida para fotografiar. Pasear con una escaleta de actividades podría ser la intención educativa para conocer un poco mejor lo ambiental. El producto sería una serie de fotografías ambientales que se comparten, se trabajan y se valoran. Aprendemos a ser y a hacer; a sentir y a respetar... Pero, también, podemos realizar proyectos en común, donde ellos somos nosotros, y viceversa. El motivo está ahí; los proyectos se hilvanan con ellos.

La supuesta conjugación en presente de indicativo del verbo fotografiar tan solo ha sido un pretexto para hablar, conocer, hacer y compartir la fotografía. Con nosotros y ellos; entre todas y todos. Una experiencia formativa que pasa siempre por tener como eje inspirador a la fotografía ambiental. Y dejemos que el alumnado se exprese y dé a comprender sus conocimientos, sus propuestas de mejora, sus incentivos críticos, sus denuncias o sus zozobras. La fotografía no solo se conjuga sino que se conjura para aprender y mejorar.

\section{Antes de cerrar el objetivo}

Todos recordamos la regla de las 3 "R", es decir, es la conocida como la de reciclaje, reducción y reutilización. No obstante, en el ámbito de la educación primaria ambiental está podría ampliarse a las 3 " $\mathrm{C}$ ". $\mathrm{O}$ sea, que seamos creativos, trabajemos en conjunto y por el cuidado de lo ambiental. 
Por un diálogo con la fotografía digital ambiental desde la educación primaria

Antes de cerrar el objetivo simbólico de la cámara o del teléfono móvil, la idea es que el alumnado tenga una buena consciencia de la educación ambiental. Las lecturas de documentos, las charlas del profesorado, la reflexión grupal y la práctica de hacer fotografía podrían ser un tablero donde asentar nuestra propuesta de responsabilidad ambiental. El alumnado de primaria no puede salir del ciclo educativo solo con formación, ha de acariciar la educación y una manera de conseguirla es acercándose a los demás, viendo y respetando el trabajo de los otros pero, igualmente, amando y comprendiendo a lo ambiental. No es cuestión de imponer sino de consensuar, no es solo fotografiar sino se trata, asimismo, de pararse serenamente a comprender. Pensamos en la cultura slow llevada al aula; la conocida como la educación slow. Pero no lo interpretaríamos solo como la calma o tomarse la vida sin precipitaciones sino, igualmente, lo asemejaríamos al tiempo que el alumnado precisa para reflexionar y metabolizar lo que está aprendiendo. Es su tiempo para comprender y disfrutar con lo que se aprende. Es el espacio de tiempo para que los demás también reconozcan nuestras aportaciones en forma de fotografía. Es, del mismo modo, una oportunidad que debemos tener para después de mirar y observar posibilidades de mejoras, de ser nosotros lo que

12 iremos a mejorar con nuestra siguiente fotografía.

Estamos ante una nueva tendencia de compromiso social donde la educación en primaria y sobre lo ambiental debería, al menos, considerarla por dos razones: a) porque da y presta atención al presente-futuro y b) pues se trata de una invitación a disfrutar con la cultura de y por la vida. Es decir, llevado al ámbito de la educación ambiental en primaria se hace necesaria por ser un modo de enseñanza-aprendizaje reflexivo, en la cual existe una pertinente inclinación a invitar a pensar atenta y detenidamente sobre esa realidad ambiental. Es una forma de proponer un trabajo al alumnado, en grupo o individualmente, de mayor calidad, donde se presta atención a los detalles, al aprender disfrutando. En gran medida con la educación slow se empiezan a quebrantar las estructuras rígidas de la enseñanza-aprendizaje y la unicidad en los resultados esperados. Aquí y ahora se establecen las conexiones necesarias entre el conocimiento y el proceso de enseñanza-aprendizaje con la gran particularidad de que se respetan los diferentes ritmos de aprendizajes del alumnado.

En este diseño determinado cabría establecer algunas bases pedagógicas inspiradas en no penalizar el error y castigarlo pues, el error, forma 
parte del proceso de aprendizaje. Y a partir de este enunciado, se establecen las bazas para impulsar la creatividad fotográfica inspirada en el principio de recuperar el proceso haciendo que el alumnado descubra su entorno. De este modo, se contribuye a la construcción del conocimiento, ya que la reflexión, la escucha y el debate se adhieren al aprendizaje social y colaborativo.

Siguiendo los principios de la educación slow (DOMĖNECH, 2009), se sugiere que la educación en sí es un proceso lento, pues es cualitativo y cada persona requiere su tiempo. Pero, igualmente, se advierte que cada aprendizaje debe realizarse en el momento oportuno. $Y$, haría falta redefinir el uso del tiempo en la educación primaria, pues, probablemente, se ha adultizado bastante en los niños. Un tiempo que da respuesta a la organización institucional pero soslaya un poco al alumnado, su diversidad y no se centra en saber encontrar los momentos precisos para que cada uno sienta placer en lo que hace, se muestre motivado y pueda seguir aprender. Y el tiempo no ha de ser sinónimo de velocidad (HONORÉ, 2008), sino que se ha de ajustar a las demandas de cada alumnado.

\section{Una vez cerrada la cámara}

Ya hemos cerrado la cámara pero no hemos dado por concluida la clase. El alumnado habrá aprendido muchos conceptos, habrá relacionado contenidos, habrá comprendido el porqué de esa idea... En definitiva, habrá aprendido (en la acepción de asimilar y comprender) e, igualmente, habrá aprehendido (en el matiz de alcanzar). A todas luces, habrá tenido y obtenido una experiencia formativa que lo ha nutrido. Los apriorismos con los que había entrado en el aula han irrumpido en confrontación con otros puntos de vistas (fotográficos y dialógicos) y, ojalá, el alumnado haya experimentado una transformación idónea y beneficiosa. Habrá crecido personalmente. Con la fotografía se habrá acercado a determinadas realidades, se le ha permitido salir e introducir estos productos ético-estéticos en el aula. Y sin haberse dado demasiada cuenta el alumnado ha aprendido una cosa muy importante: a verse reflejado en las fotografías que hace. Pues habrá intuido que existe una relación de estrecha reciprocidad entre lo real, la realidad fotografiada y el autor de la obra (SONTAG, 2014). 
Otra consideración final se centraría en la posibilidad de innovar con la fotografía digital ambiental. Definir el concepto innovación en educación es algo arduo y complicado pero realizando un ejercicio de concreción podríamos decir que se trata de una actuación que introduce lo nuevo con la intención de producir un cambio y, por tanto, mejorar (CARBONELL, 2015). En cierto modo, es crear algo nuevo o, en su defecto, modificar lo que existe para renovar. La innovación lleva implícito parte de creatividad, con un resultado dual: a) solucionar una situación y b) facilitar una tarea.

Y este supuesto ejercicio de innovación, con la intención de motivar al alumnado de primaria, podría pasar por la inclusión en la dinámica de clase de nuevas herramientas tecnológicas que no sean muy complicadas para los estudiantes. Y, en este sentido, proponemos utilizar la aplicación Fotobabble. Una manera de hacer hablar a la fotografía; es decir, ponerle voz a la fotografía; un pie de foto sonoro. Es un modo de añadir una grabación de audio, de un minuto, a una fotografía. A la postre, es una forma de que el alumnado describa sus imágenes... Y, a partir de este momento, introducimos otro aliciente innovador que podría ser interpretado por el alumnado como motivador.

De esta manera hemos intentado poner de relieve la importancia de la

14 fotografía ambiental en y desde la educación primaria. Una fotografía que no solo retrata la realidad sino, también, las intenciones de quién la hace. Y detrás de una buena fotografía ambiental está el alumnado sensibilizado y, a su lado, el profesorado cualificado.

\section{Referencias}

ÁlVAREZ, Pedro; VEGA, Pedro. Actitudes ambientales y conductas sostenibles. Implicaciones para la educación ambiental. Revista de Psicodidáctica, Vizcaya, v. 14, n. 2, p. 245-260, enero. 2009.

APARICI, Roberto; GARCÍA, David. Comunicar y educar en el mundo que viene. Barcelona: Gedisa, 2018.

AVELLO-MARTÍNEZ, Raidell; MARíN, Victoria La necesaria formación de los docentes en aprendizaje colaborativo. Profesorado, Granada, v. 20, n. 3, p. 687-713, nov. 2016. Disponible en: hitps://recyt.fecyt.es/index.php/profesorado/article/view/54603. Acceso el: 4 oct. 2020 
AYALA, Ana. La clase al revés. Las lecciones, en casa y las tareas, en clase. Educación 3.0, n. 13, p. 12-22, inv. 2014.

BARTHES, Roland. La cámara lúcida. Nota sobre la fotografía. Barcelona: Paidós, 1990.

BERGER, John. Para entender la fotografía. Barcelona: Gustavo Gili, 2015.

BILBAO, Naiara; MARAURI, Jesús. Experiencias de aprendizaje dialógico en educación superior: lecturas y bibliotecas tutorizadas. Revista hachetetepé, Cádiz, n. 4, p. 103116, nov. 2012. Disponible en: https://revistas.uca.es/index.php/hachetetepe/article/ view/6368/6469. Acceso el: 5 oct. 2020

CABERO, Julio. Tendencias educativas para el siglo XXI. Madrid: Centro estudios financieros, 2016.

CABERO, Julio; GARCÍA, Francisco. Realidad aumentada: tecnología para la formación. Madrid: Síntesis, 2016.

CAMBIL, María de la Encarnación; TUDELA, Antonio. Educación y patrimonio cultural. Fundamentos, contextos y estrategias didácticas. Madrid: Pirámide, 2017.

CANTÚ-MARTÍNEZ, Pedro. Educación ambiental y la escuela como espacio educativo para la promoción de la sustentabilidad. Revista Electrónica Educare, San José de Costa Rica, v. 18, n. 3, p. 39-52, sep./dic. 2014 Doi: http://dx.doi.org/10.15359/ree. 18-3.3. Acceso el: 20 oct. 2020.

CARBONELL, Jaume. Pedagogías del siglo XXI: alternativas para la innovación educativa. Barcelona: Octaedro, 2015.

DOMĖNECH, Joan. Elogio de la educación lenta. Barcelona: Graó, 2009.

FISHER, Robert. Diálogo creativo. Hablar para pensar en el aula. Madrid: Morata, 2013.

FREEMAN, Michael. El ojo del fotógrafo: composición y diseño para crear mejores fotografías digitales. Barcelona: Blume, 2016.

GARCÍA, Mónica. El uso de la imagen como herramienta de investigación. Campos, Bogotá, v. 1, n. 2, p. 363-372, jul./dic. 2013. Disponible en: https://issuu.com/universidadsantotomas/docs/campos_2. Acceso el: 11 sep. 2020.

HERRÁN, Agustín de la j’Y si nuestra educación estuviese radicalmente equivocada? In: MEDINA, Antonio; de la HERRÁN, Agustín; DOMíNGUEZ, María (coord.). Nuevas perspectivas en la formación de profesores. Madrid: Universidad Nacional de Educación a Distancia (UNED), 2017. 
Por un diálogo con la fotografía digital ambiental desde la educación primaria

HONORÉ, Carl. Elogio de la lentitud. Barcelona: RBA, 2008.

JAUSS, Hans Robert. Caminos de la comprensión. Madrid: Antonio Machado, 2012.

JEFFREY, lan. 2011 . Cómo leer la fotografía: entender y disfrutar los grandes fotógrafos de Stieglitz a Doisneau. Barcelona: Electa, 2011.

LÓPEZ-MARTÍNEZ, Olivia; NAVARRO-LOZANO, Juan. Creatividad e inteligencia: un estudio en Educación Primaria. Revista de educación educativa, Murcia, v. 28, n. 2, p. 283-297, nov. 2010.

MARTA-LAZO, Carmen; GABELAS, José. Comunicación digital. Un modelo basado en el factor relacional. Barcelona: Ediciones UOC, 2016.

MARZAL, Javier. Cómo se lee una fotografía: interpretaciones de la mirada. Madrid: Cátedra, 2008.

NAVARRO, Fructuoso. Las claves de una buena foto: introducción a la fotografía digital. Madrid: Anaya, 2019.

RIGO, Daiana. Aprender y enseñar a través de imágenes. Desafío educativo. ASRI, Madrid, n. 6, abr. 2014. Disponible en: https://www.researchgate. net/publication/261875839_ 16 Aprender_y_ensenar_a_traves_de_imagenes_desafio_educativo. Acceso el: 15 oct. 2020.

RIVAS, Rodrigo. La Fotografía móvil. Madrid: Anaya, 2018.

RODRÍGUEZ-ORTIZ, Angélica; MONTOYA-TRUJILLO, Betty. La fotografía como estrategia para formar en ciudadanía. Revista Jangwa Pana, Santa Marta, v. 19, n. 1, enero/abr. 2020. DOl: https://doi.org/10.21676/16574923.3359. Acceso el: 11 oct. 2020.

SALKELD, Richard. Cómo leer una fotografía. Barcelona: Gustavo Gili, 2014.

SONTAG, Susan. Sobre la fotografía. Barcelona: Debolsillo, 2014.

Subirana, Victoria. La pedagogía transformadora. Madrid: UNED, 2015.

TÓJAR, Juan; RODRÍGUEZ, Mena. La fotografía: de la investigación cualitativa a la formación en educación ambiental. Hachetetepé. Revista científica De Educación Y Comunicación, Cádiz, n. 6, p. 27-35, nov, 2013. Disponible en: https://revistas.uca.es/index.php/ hachetetepe/article/view/6314. Acceso el: 5 de oct. 2020.

TRINQUELL, Agustina. Hacer(lo) visible la imagen fotográfica en la investigación social. Reflexiones, San José de Costa Rica, v. 94, n. 2, p. 121-132, nov. 2015. Disponible en: https://www.redalyc.org/pdf/729/72946471009.pdf. Acceso el: 21 oct. 2020. 
Prof. Dr. Víctor Amar

Universidade de Cádiz (Espanha) Grupo de Pesquisa Educación y Comunicación Orcid id: 0000-000 1-9036-265 1

E-mail: victor.amar@uca.es

Recebido: 18 nov. 2020

Aceito 1 dez. 2020 